\title{
A new approach to calculate extreme storm surges: analysing the interaction of storm surge components
}

\author{
G. Gönnert \& K. Sossidi \\ Agency of Roads, Bridges and Waters, \\ Free and Hanseatic City of Hamburg, Germany
}

\begin{abstract}
The North Sea coast is, as well as many coastal regions, a preferred residential and industrial area. At the same time the North Sea coast is seriously threatened by storm surges. Climate change and resulting consequences will have severe effects on the safety in coastal areas. The Project XtremRisK - Extreme Storm Surges at Open Coasts and Estuarine Areas, Risk Assessment and Mitigation under Climate Change Aspects, will assist in facing this challenge. The "SourcePathway-Receptor"-Concept will be used as a basis for risk analysis and development of new management strategies.

Within the XtremRisK project, a method to assess extreme events will be developed which takes the hydrodynamics of storm surges into account. With this method, the components of a storm surge, tide, wind surge and external surge, and their interaction will beanalysed. The study focuses on analysing (i) the highest event of each component and (ii) the interaction between tide and surge as well as the interaction between surge and external surge. This detailed analysis is needed because the components do not interact linearly. With this knowledge, an extreme event based on the observed extremes of the components can be calculated. Non-linear addition leads to a lower water level than in case of linear superposition. With this approach, an extreme event can be calculated in accordance with natural law.Subsequently, extreme events will be assessed using conditions which reflect the climate change scenarios.
\end{abstract}

Keywords: storm surges, North Sea, extreme events, non-linearity, coastal protection, design level. 


\section{Introduction}

Climate change and the resulting consequences like sea level rise may have serious consequences on the safety of people and assets in coastal areas. To evaluate these consequences, it is necessary to first assess extreme storm surge events. In a second step scenarios of potential sea level rise are identified and investigated. These extreme scenarios are necessary for risk analyses and moreover can be used for design level.

The project XtremRisK (Extreme Storm Surges at Open Coasts and Estuarine Areas - Risk Assessment and Mitigation under Climate Change Aspects) aims to design approaches to meet the challenge of the future. The project is funded by the German Federal Ministry of Education and Research (BMBF) and was launched in October 2008.

Within the project, integrated risk analyses will be conducted and risk management policies for open coasts (pilot site Sylt Island) and estuarine areas (pilot site Hamburg) will be developed. The integrated flood risk analysis is based on the source-pathway-receptor concept (figure 1).

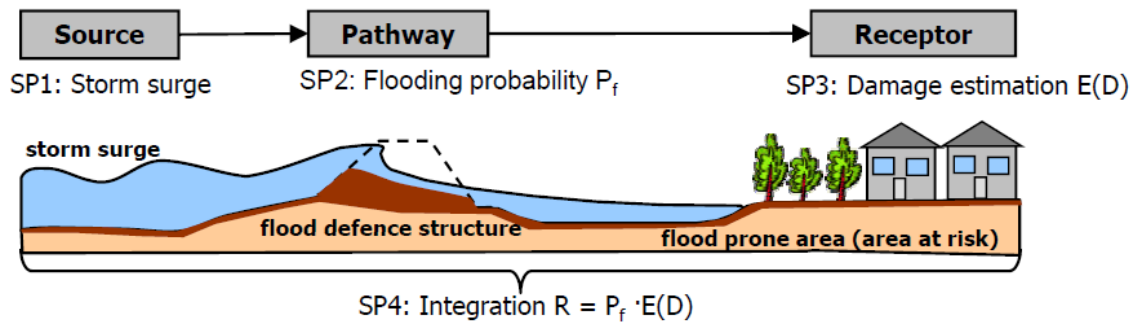

Figure 1: Source-pathway-receptor concept.

This paper illustrates the approach to calculate physically possible extreme storm surges developed in subproject 1a. With this method, the three main components of a storm surge, tide, wind surge and external surge, will be analysed and their development over time will be assessed.

The focus lies on the analysis of (i) the highest observed occurence of each component and (ii) the interaction between tide and wind surge and the interaction between storm surge and external surge. This detailed analysis is needed because the components do not interact linearly. Investigation on the hydrodynamics and physics of storm surges have shown that the components have to be added non-linearly (e.g. Tang et al. [1]; Horsburgh and Wilson [2]; Jones and Davies [3]), which leads to a lower water level than in case of linear superposition. With this knowledge an extreme event based on the maximum components can be calculated. The result is a realistic extreme scenario under present climate conditions. 


\section{Pilot sites}

The analyses are conducted for one location at the open coast (Island of Sylt) and another, which is situated in an estuarine area (city of Hamburg). The chosen study sites allow for transferability of the developed methods to other coastal or estuarine areas.

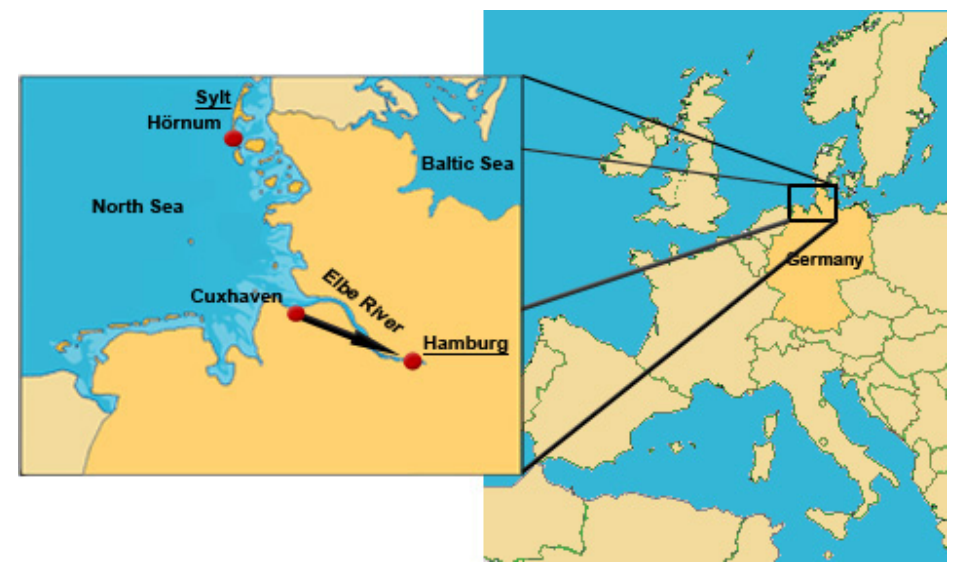

Figure 2: $\quad$ Location of the pilot sites Hamburg and Sylt.

The city of Hamburg is the second largest city of Germany. About 1.8 million people live in this megacity which is a centre for trade, transportation and services and an important industrial site. Furthermore, the port of Hamburg is the largest seaport in Germany.

The Island of Sylt is the biggest of the North Frisian Islands. With its $40 \mathrm{~km}$ of beach at the west side it is one of the most popular touristic places in Germany. Due to its exposed position in the North Sea it is vulnerable to severe erosion during storm surges.

For the characterisation of storm surges, a long consistent time series of water level observations is needed. Consequently the extreme storm surge for the city of Hamburg will be determined at tidal gauge Cuxhaven and its propagation upstream to Hamburg subsequently calculated by numerical modeling. The storm surge for Sylt will be determined at the tidal gauge Hörnum.

The approach of the analysis of extreme storm surges and the single components will be presented below. It was developed at tidal gauge Cuxhaven, because this is the best evaluated tidal gauge in Germany with a continuous time series that reaches back to 1900 .

\section{The methodological approach}

The chosen approach is based on a deterministic procedure that takes into account the hydrodynamic interactions of the storm surge components as well as 
their meteorologic context. In a first step all observed storm surges are separated into their components wind surge, tide and external surge and the highest event of each component is detected (figure 3).

For the construction of extreme storm surge events it is essential to consider the highest observed occurrence of each component. Since these extreme values appeared in different storm surge events one has to combine them in a new storm surge event. To receive a result that corresponds with physical law the non-linear interaction of the storm surge components have to be taken into account. Considering this, the calculated extreme storm surge is a feasible event in fact.

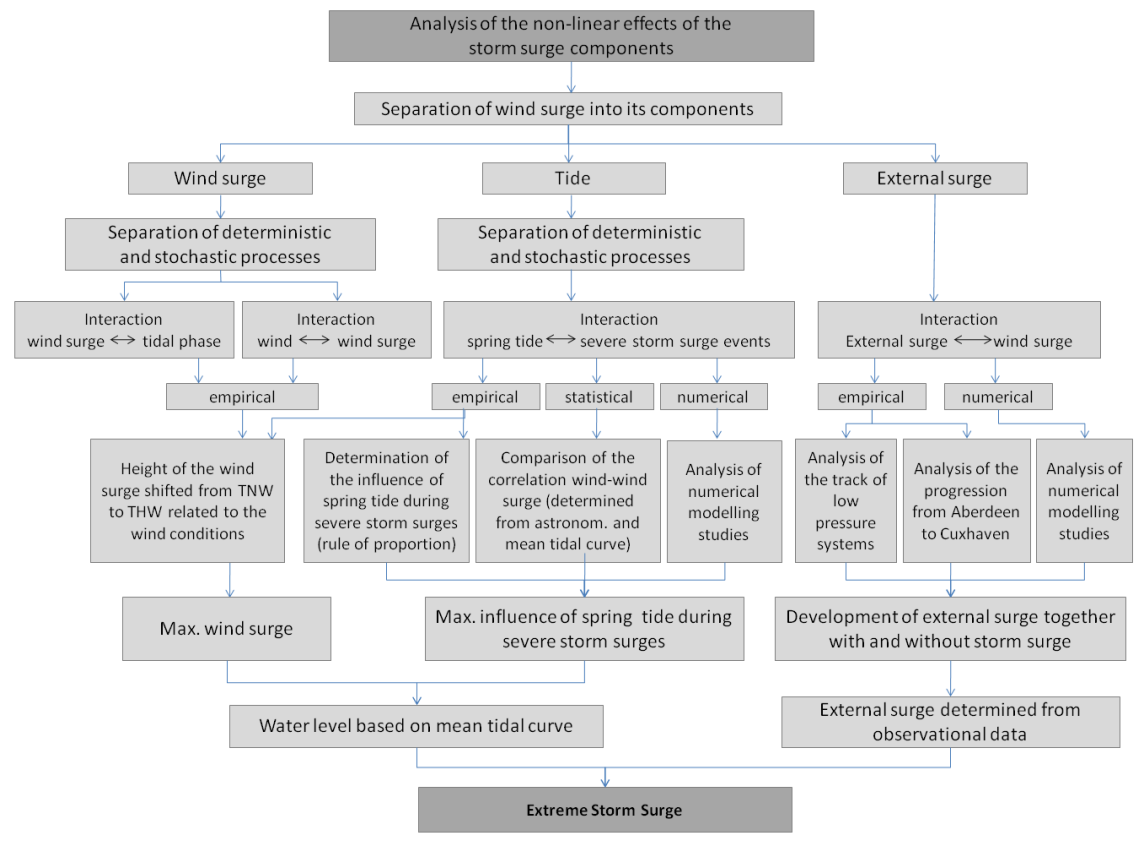

Figure 3: $\quad$ Methods to estimate the non-linear effects.

Before combining the components to a new storm surge, it is required to examine the physical possibility of the coincidence of the observed maximum values of the components. Therefore the possibility of a simultaneous occurrence of a high spring high tide, external surges and high wind surge at tidal gauge Cuxhaven is examined.

In the course of a comprehensive analysis the components are firstly scrutinized separately and secondly their interaction is investigated with empirical, statistical and numerical methods. The consistence of the different methods' results allows an optimal ascertainment of the physical context and a validation of the used methods. The non-linear interaction is worked out. Finally, the highest observed values of each component are added non-linearly following natural law to receive an extreme storm surge event. 


\subsection{The components of a storm surge}

The wind is the main reason for the formation of a storm surge. It pushes the water against the coast causing higher water levels than the ordinary sea level which is influenced by the tides. The tidal range reaches its maximum at spring tide so that during spring tides high waters rise extra high. The water level at the North Sea coast can also be raised by external surges that are generated by cyclones over the Northeastern Atlantic and propagate into the North Sea (Lundbak [4]; Timmerman [5]), pushing additional water masses into the basin. The coincidence of wind surge, spring high tide and external surge leads to extreme storm surge levels along the coast (figure 4).

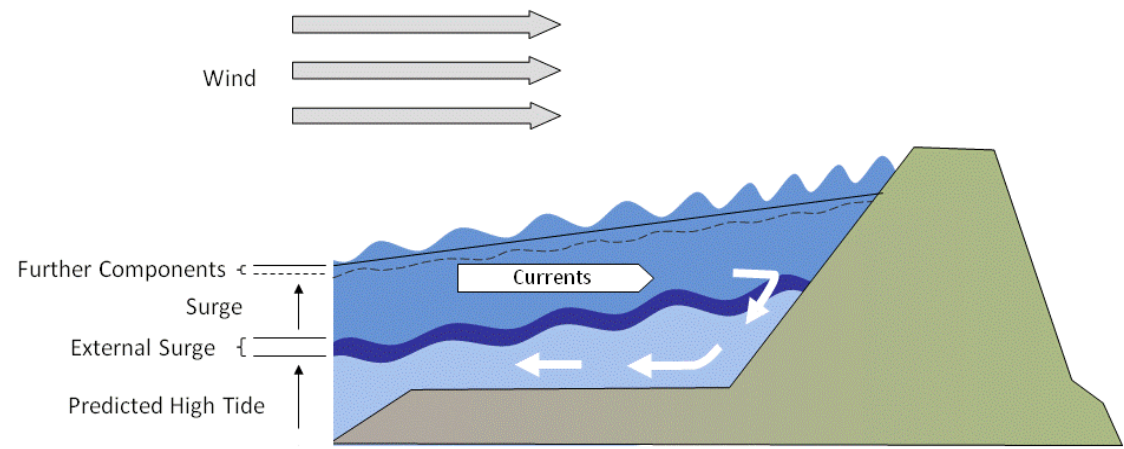

Figure 4: The components of a storm surge.

Thus a storm surge is composed of the local tides, wind surge and a possible external surge. In the project storm surges from 1901 until 2008 at tidal gauge Cuxhaven and from 1936 to 2008 were analysed and decomposed into wind surge, external surge and astronomical tide. These three components will be outlined in the following subchapters.

\subsubsection{Wind surge}

Wind surge is caused by wind-induced onshore surface current. The wind direction that produces the highest wind surge at tidal gauge Cuxhaven is $295^{\circ}$ (westerly to north-westerly winds). At tidal gauge Hörnum it is $267^{\circ}$ (westerly winds). The wind causes a rise of the water near the coast and hence a tilt of the water surface of the North Sea from the deep water area towards the coast. The height of the wind surge depends on wind speed and wind direction.

A formula to calculate wind surge as a function of wind speed and wind direction exists only for few tidal gauges at the German North Sea coast. Therefore wind surge is generally calculated by subtracting the astronomical tide (or the mean tide) from the observed tide. In case of using the astronomical tide for calculation, the wind surge also contains other factors that are not caused by the wind, like the effect of local air pressure or the external surge. Due to this 
circumstance it was examined which of the storm surges since 1901 occurred simultaneously with an external surge before conducting further analyses.

The analyses of the data showed that the wind surge maximum can occur to all tidal phases, but mostly occurs around tidal low water. The highest wind surge maxima also occurred around tidal low water. This confirms earlier studies that indicated that the maximum wind surge tends not to coincide with high tide (e.g. Keers [6]; Horsburg and Wilson [2]).

The highest wind surge event at tidal gauge Cuxhaven that is not influenced by an external surge consequently reached a height of $4.15 \mathrm{~m}$. It occurred in January 1976 around low tide.The highest wind surge event at tidal gauge Hörnum features $3.50 \mathrm{~m}$. It occurred in January 1990 around low tide.

\subsubsection{Spring tide}

Tide is caused by the gravitational forces of the sun and moon. At new and full moon the tidal powers of moon and sun amplify each other causing very high and very low tides which are called spring tides. At half moon these powers cancel each other partly so that the tides, that are called neap tides, are not as dramatically high and low.

The mean tidal curve is the arithmetical averaged observed tidal curve at a specific gauge of a certain time period. Thereby tidal curves of different moon phases are averaged so that the differences of spring and neap tide are indeterminable. The past analyses of storm surges were based on the mean tide because of pragmatically reasons: The mean tide is a statistical term which needs only relatively short calculation time (Siefert [7]). In the past it was mathematically difficult and a time-consuming intent to calculate the astronomical tide for any day. Nowadays there are computer programs that make it possible to calculate the astronomical tide in a comparable time frame to the mean tide. Thus it is possible to divide the astronomical effects from the wind effects and to analyse the tide-surge-interaction.

The highest values of spring high tide at the tidal gauges were detected by subtracting the mean high tide from astronomical high tide. In Cuxhaven it was $60 \mathrm{~cm}$, in Hörnum it was $63 \mathrm{~cm}$.

\subsubsection{External surge}

External surges are generated in the Northeastern Atlantic due to of air pressure variations that are generated by fast passing cyclones. They produce observable waves at the water surface as well as internal waves in the water body. The propagation of an external surge into the North Sea takes place in preference when the track of the causative cyclone leads from the sea areas between Ireland and Iceland to Mid-Norway (Schmitz and Habicht [8]). These waves propagate to the North Sea similar to a tide wave, but independent of tide phase and any periodic regularity and travel through the North Sea in counterclockwise direction.

External surges are calculated out of observed tide data at tidal gauge Cuxhaven that were recorded from the Federal Maritime and Hydrographic Agency (Gönnert [9]). Their height is calculated by subtracting the astronomical tide, wind surge and the effect of local air pressure from the observed low and 
high waters. The calculated values still may contain components besides the external surge. These are seiches, effects of air pressure and air pressure variations over the North Sea, effects of water temperature and temperature difference between air and water. This variety of potential causes for an increase of the water level reveals the necessity of a precise definition of external surges. So, residual surges are only defined as external surges if they can also be indentified at tidal gauge Aberdeen and Immingham at the British coast (Gönnert [9]).

The maximum height of an external surge recognised at Cuxhaven was 109 $\mathrm{cm}$. This external surge reached $108 \mathrm{~cm}$ in Aberdeen. It did not coincide with a storm surge. The highest external surge that coincided with a storm surge reached a peak level of $1 \mathrm{~m}$ at Cuxhaven. Each fifth to sixth storm surge at tidal gauge Cuxhaven occured at the same time as an external surge (Gönnert [9]).

For tidal gauge Hörnum no records of external surges exist. Since external surges travel through the North Sea similarly to the tide (Banner et al. [10]; Pugh [11]), the external surges detected at tidal gauge Cuxhaven are shifted to Hörnum with the observed tide to estimate the time of occurrence at that tidal gauge. For the detected time periods, the height of external surges at tidal gauge Hörnumwill be calculated following the method used at tidal gauge Cuxhaven.

\subsection{Investigations of the non-linear interaction}

When calculating an extreme storm surge it has to be taken into account that the components of a storm surge do not superimpose linearly. Their interaction is non-linear, dependent on the water depth. The wind-induced onshore surface current generates an offshore-directed bottom return current. This return current increases with rising water level near the coast which in turn leads to a stronger decrease of the water level. Consequently, taking this physical law into account when calculating storm surge events leads to lower storm surge levels than linear superposition.

A comprehensive analysis of non-linear interactions between the storm surge components is carried out by combining empirical, statistical and numerical methods (figure 3). This analysis makes it possible to work out the effect of nonlinear interaction when combining the maximum values of the components to receive the extreme storm surge's curve and peak water level at high tide. The results are presented using the example of Cuxhaven.

\subsubsection{Non-linear interaction between tide and wind surge}

To detect the highest observed wind surge, the wind surge curve was calculated for around 250 storm surge events. The winds surge curve was calculated by subtracting the astronomical tide from the observed tide as well as by subtracting the mean tide from the observed tide. Doing that, one can identify the effect of the astronomical dissimilarity on the wind surge.

The calculation of the wind surge curve for the whole storm surge period makes it possible to determine a maximum wind surge peak regardless of tide phase for each storm surge. The highest observed wind surge values occur around low water. Since there is no cohesion between tide phase and wind the 
maximum force of wind can also occur at other tide phases such as high water. The data show that the height of wind surge is less around high water, though.

To determine the ratio between wind surge height around low water and around high water the relations between wind surge, the respective wind speed and tide are analysed.Based on the wind directions that produce the highest wind surge at tidal gauge Cuxhaven (see subchapter 3.1.1) the effective wind is calculated. It describes the wind speed converted to the wind direction that produces the highest wind surge. The analysis of wind surge depending on effective wind to each tide phase showed the relation between the height of wind surge around high tide and around low tide. At tidal gauge Cuxhaven, the wind surge at high tide accounts for 82 to 94 percent of the wind surge around low tide. The amount of remaining wind surge rises with the effective wind speed.

This ratio makes it possible to detect the highest wind surge around high tide by shifting the observed wind surge events to high tide and reducing their height as appropriate. The precondition for this shifting is that the respective effective wind acts over an extended amount of time.

The highest wind surge event around high water at tidal gauge Cuxhaven that is not influenced by an external surge features $3.70 \mathrm{~m}$. It occurred in January 1976 around high tide and does not have to be shifted. During this storm surge event the wind surge reached $4.15 \mathrm{~m}$ around previous low tide. The wind did not change during that time, so the observed wind surge values are equivalent to a reduction of 89 percent.

When wind surge coincides with spring high water it has to be investigated to which amount this astronomically induced increase of the water level affects the storm surge water level. For this investigation three different methods are used:

- Statistical analysis of the correlation between effective wind and wind surge determined from astronomical tide and mean tidal curve

- Analysis of numerical modelling studies

- Calculation of the spring tide influence on an extreme event.

The investigations on spring tide are based on the calculation of astronomical tide curves with a non-harmonically method. The cross-correlation shows the only small effect of the astronomically induced deflection of water level on the wind surge curve and peak. This result matches with the results of numerical modeling studies by Dick [12] that showed that the effect of the astronomical dissimilarity decreases as the wind surge increases.

The analysis of the relation between the height of wind surge around high tide and around low tide clarified the increasing relevance of the wind with increasing wind speed. It can be transferred to the astronomical dissimilarity. Hence the amount of reduction of wind surge due to shifting from low water to high water can be adapted to make out the reduction of effects of spring tide on storm surge water levels. Because there is a connection between overall water level and reduction, the calculation of the astronomical dissimilarity's decrease has to be made including wind surge.

For Cuxhaven, the astronomical dissimilarity in combination with the wind surge of $3.70 \mathrm{~m}$ reduces to $10 \mathrm{~cm}$. At tidal gauge Hörnum the amount of spring tide reduces to about $44 \mathrm{~cm}$ when coinciding with a wind surge of $3.19 \mathrm{~m}$. 


\subsubsection{Non-linear interaction between storm surge and external surge}

The cyclone that causes an external surge in the Atlantic Ocean has negligible to substantial effects on the water level in the North Sea, depending on the cyclone's track. The investigation of the development of the external surges from Aberdeen to Cuxhaven via Immingham showed that most of the external surges increased in height on their way from Aberdeen to Immingham and decreased again on the way to Cuxhaven so that they are smaller in Cuxhaven than in Aberdeen (Gönnert [9]). When the development in height of each external surge is connected with the respective meteorological situation it shows that:

- external surges will increase, if the cyclone tracks southwards and influences the water body of the North Sea (and sometimes produces a storm surge).

- external surges decrease (or stays more or less same level), if the cyclone tracks northwards and has no relevant influence on the water body of the North Sea (figure 5).

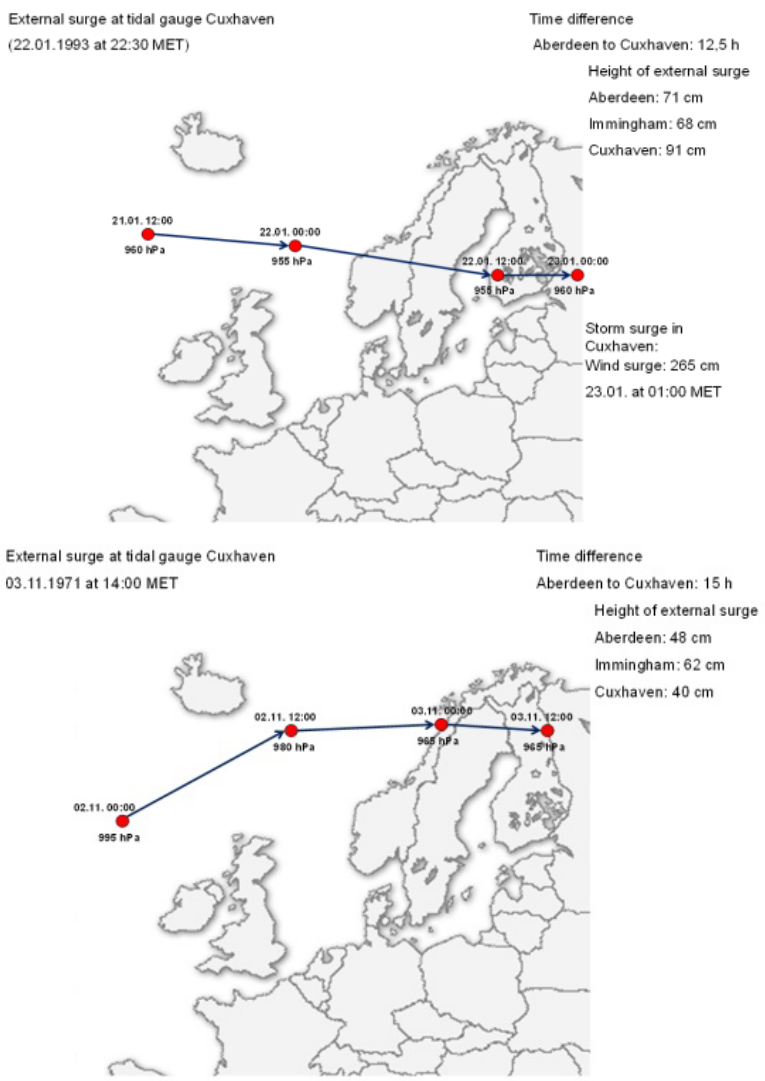

Figure 5: Different tracks of cyclones and their influence on external surges. 
When the cyclone features a southern track the water level in the North Sea can for instance be affected by effects of air pressure and air pressure variations over the sea as well as additional wind. To avoid that the peak of the external surge combined with the extreme storm surge contains alterations of the water level due to these influences, only the external surges are taken into account that occurred without a coinciding storm surge. The average decrease of these external surges between Aberdeen and Cuxhaven is 30 percent.

The highest observed external surge reached $1.08 \mathrm{~m}$ at tidal gauge Aberdeen. If reduced by 30 percent on its way to Cuxhaven, it arrives there with a peak of about $80 \mathrm{~cm}$. This equates the peak of the external surge that was observed during the storm surge of 1962 .

\subsection{Calculation of an extreme storm surge event}

The extreme storm surge is calculated by adding the highest observed values of each storm surge component in due consideration of their non-linear interaction investigated in this study and adding the resulting value to the mean high tide.

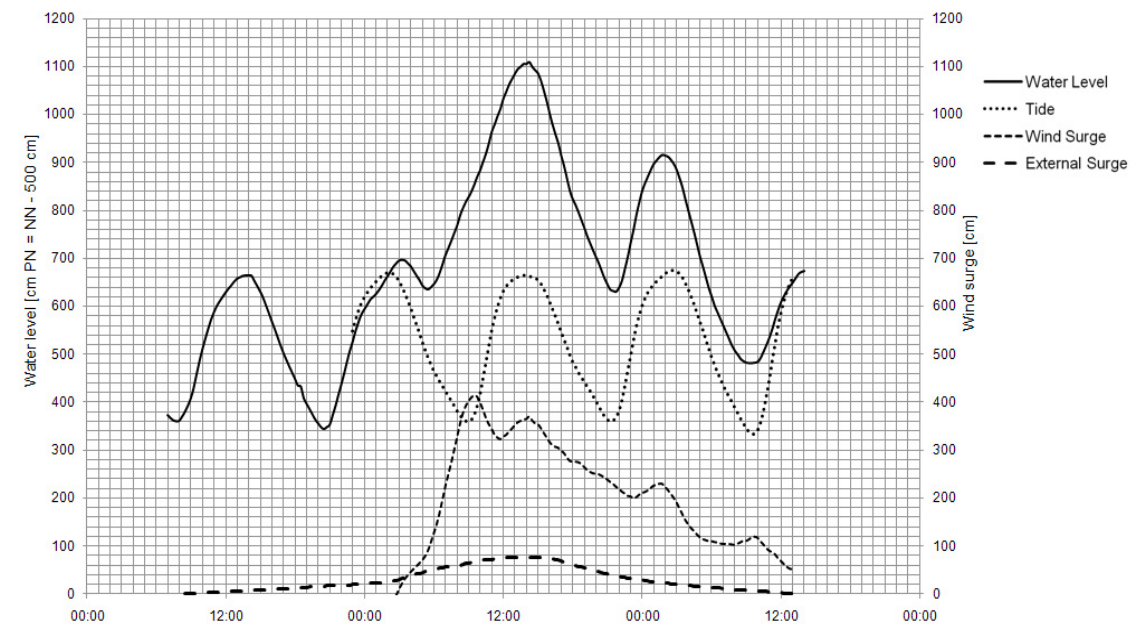

Figure 6: The extreme storm surge and its components at tidal gauge Cuxhaven.

The wind surge curve that is a constituent of the constructed storm surge curve is characteristic for a severe storm surge event at the respective tidal gauge. The storm surge curve is composed by the wind surge curve, the external surge curve and an astronomical tide curve that reflects the mean tide condition plus the detected effect of the astronomical dissimilarity. Figure 6 shows the constructed extreme storm surge at tidal gauge Cuxhaven.

To gain the storm surge curve at tidal gauge St. Pauli/Hamburg the propagation of the extreme storm surge determined at tidal gauge Cuxhaven upstream to Hamburg will be calculated by numerical modelling. 


\section{Summary}

This paper presents an empirical approach to determine extreme storm surges at different tidal gauges. Statistical and numerical methods are brought in to validate the empirical methods. The approach takes into account the storm surges components wind surge, tide and external surge. It focuses on (i) the analysis of the highest event of each component and (ii) the analysis of the interaction between tide and surge and the interaction between surge and external surge to (iii) calculate an extreme storm surge event based on the result of the analyses. The consideration of the non-linear effects between the storm surge components leads to a lower water level than in case of linear superposition.

Since the resulting value is added to the mean high tide, climate change can be taken into account by adding the potential sea level rise to the mean tide.

The presented approach is developed at tidal gauge Cuxhaven because of its continuous time series that reaches back to 1900 . It is then transferred to tidal gauge Hörnum. The implementation at this second tidal gauge showed that, provided that an adequate series of data is available, the approach can be transferred to other study areas.

\section{References}

[1] Tang, Y.M., Grimshaw, R., Sanderson, B. \&Holland, G., A Numerical Study of Storm Surges and Tides, with Application to the North Queensland Coast. Journal of Physical Oceanography, 26, pp. 2700-2711, 1996.

[2] Horsburgh, K.J. \& Wilson, C., Tide-surge interaction and its role in the distribution of surge residuals in the North Sea. Journal of Geophysical Research, 112 (C8). Art. No. C08003. 10.1029/2006JC004033, 2007.

[3] Jones, J.E. \& Davies, A.M., Influence of non-linear effects upon surge elevations along the west coast of Britain. Ocean Dynamics, 57, pp. 401416, 2007.

[4] Lundbak, A., The North Sea Storm Surge of February 1, 1953. Its Origin and Development. GeografiskTidsskrift, 54(1), pp. 8-23, 1955.

[5] Timmerman, H., On the Importance of Atmospheric Pressure Gradients for the Generation of External Surges in the North Sea. Deutsche HydrographischeZeitschrift, 28(2), pp.62-71, 1975

[6] Keers, J.F., An empirical investigation of interaction between storm surge and astronomical tide on the east coast of Great Britain. Ocean Dynamics,21(3), pp. 118-125, 1968

[7] Siefert, W., Sturmflutvorhersagen für den Tidebereich der Elbe aus dem Verlauf der Windstaukurven in Cuxhaven. Mitteilungen des FranziusInstituts für Grund- und Wasserbau der TU Hannover, 30, pp. 1-142, 1968

[8] Schmitz, H.P. \& Habicht, D., Barotropic numerical experiments on external surge generation at the edge of the north-western European shelf. GerlandsBeiträgezurGeophysik, 97/5, pp. 422-437, 1988 
[9] Gönnert, G., Sturmfluten und Windstau in der Deutschen Bucht. Charakter, Veränderungen und Maximalwerte im 20. Jahrhundert. Die Küste, 67, pp. 185-365, 2003

[10] Banner, F.T., Collins, M.B. \&Massie, K.S., The North-West European shelf seas: the sea bed and the sea in motion V. 2, Elsevier, Amsterdam, 1979

[11] Pugh, D.T., Changing Sea Levels: Effects of Tides, Weather and Climate. Cambridge Univ. Press, Cambridge, 2004

[12] Dick, S., Die Sturmflut am 3. Dezember 1999 - Fallstudien mit dem Windstaumodell des BSH. Presentation at the workshop on storm surges organized by the Federal Waterways Engineering and Research Institute, Hamburg, 16.11.2000, Head of the Directorate Forecasting, Federal Maritime and Hydrographic Agency, Hamburg, Germany 